Manchester, UK; ${ }^{5}$ Boehringer Ingelheim, Burlington, Ontario, Canada; ${ }^{6}$ Boehringer Ingelheim Pharma GmbH and Co. KG, Ingelheim, Germany; 'Boehringer Ingelheim Pharmaceuticals Inc, Ridgefield, Connecticut, USA; ${ }^{8}$ Los Angeles Biomedical Research Institute at Harbor-UCLA Medical Center, Torrance, Los Angeles, California, USA

\subsection{6/thoraxjn-2014-206260.378}

Background Both tiotropium $(\mathrm{T})$ and olodaterol $(\mathrm{O})$ monotherapies improve exercise endurance in patients with chronic obstructive pulmonary disease (COPD).

Objective To evaluate the effects of $\mathrm{T}+\mathrm{O}$ fixed-dose combination on exercise endurance in patients with Global initiative for chronic Obstructive Lung Disease (GOLD) 2-3 COPD after 12 weeks.

Methods TORRACTO (NCT01525615) was a 12-week, doubleblind, parallel-group, placebo-controlled, Phase III study. Patients with GOLD 2-3 COPD received $\mathrm{T}+\mathrm{O}(5 / 5 \mu \mathrm{g}$ or $2.5 / 5 \mu \mathrm{g})$ or placebo once daily via Respimat ${ }^{\circledR}$ Soft Mist ${ }^{\mathrm{TM}}$ inhaler. Primary end point was endurance time during constant work-rate cycle ergometry to symptom limitation after 12 weeks. Endurance time during endurance shuttle walking to symptom limitation after 12 weeks was also assessed in a subset of 165 patients. Other end points included pre-exercise inspiratory capacity.

Results 404 patients (269 men) were randomised (full analysis set $\mathrm{n}=385)$. Mean post-bronchodilator forced expiratory volume in 1 second was $1.66 \mathrm{~L}$ (58.6\% predicted). Endurance time during cycle ergometry was significantly increased by $14 \%$ with $\mathrm{T}+\mathrm{O} 5 / 5 \mu \mathrm{g}$ versus placebo at 12 weeks. Increases in endurance time during endurance shuttle walking were observed for both $\mathrm{T}$ $+\mathrm{O}$ doses versus placebo at 12 weeks $(21 \%$ increase, nominal $\mathrm{p}$ $=0.06$ for each dose). Both $\mathrm{T}+\mathrm{O}$ doses increased pre-exercise inspiratory capacity versus placebo at 12 weeks $(\mathrm{T}+\mathrm{O} 5 / 5 \mu \mathrm{g}$, $234 \mathrm{~mL} ; \mathrm{T}+\mathrm{O} 2.5 / 5 \mu \mathrm{g}, 207 \mathrm{~mL}$; nominal $\mathrm{p}<0.0001)$. No safety concerns were identified.

Conclusions $\mathrm{T}+\mathrm{O} 5 / 5 \mu \mathrm{g}$ improved endurance time during cycle ergometry versus placebo.

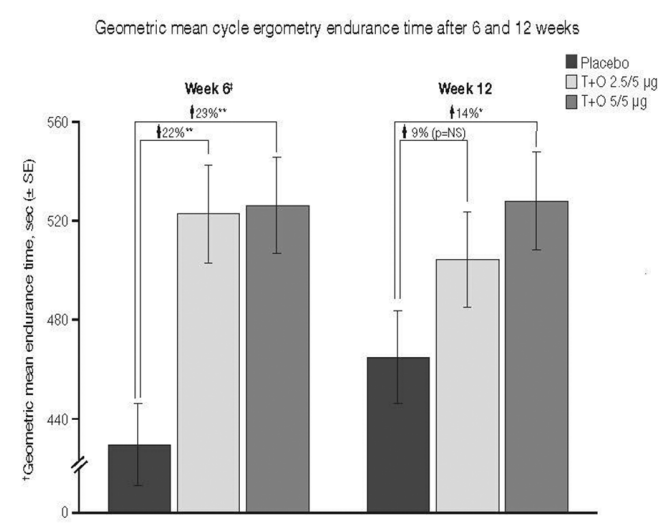

Abstract P250 Figure 1 Geometric mean cycle ergom.etry endurance time after 6 and 12 weeks

${ }^{\dagger}$ Geometric mean results reported as primary analysis based on $\log _{10}$-transformed data ${ }^{\ddagger}$ No

$\mathrm{t}$ included in hierarchical testing sequence; to be considered descriptive only Geometric mean baseline endurance time: $443.0 \mathrm{sec}$

Patient numbers: placebo $=121 ; \mathrm{T}+02.5 / 5 \mu \mathrm{g}=129 ; \mathrm{T}+05 / 5 \mu \mathrm{g}=135$

${ }^{*} \mathrm{p}<0.05$; **nominal $\mathrm{p}<0.0005$ for difference from placebo

$\mathrm{SE}$, standard error; NS, not significant
P251 EFFICACY AND SAFETY OF ONCE-DAILY INDACATEROL/ MOMETASONE COMPARED WITH TWICE-DAILY SALMETEROL/FLUTICASONE IN PATIENTS WITH MODERATE TO VERY SEVERE COPD

${ }^{1}$ Anne-Marie Kirsten, ${ }^{2}$ Alexia Richard, ${ }^{2}$ Ana-Maria Tanase, ${ }^{3}$ Cao Weihua, ${ }^{2}$ Motoi Hosoe, ${ }^{2}$ Bettina Hederer. 'Pulmonary Research Institute at Lung Clinic Grosshansdorf, Airway Research Center North, German Center for Lung Research, Grosshansdorf, Germany; ${ }^{2}$ Novartis Pharma AG, Basel, Switzerland; ${ }^{3}$ Novartis Pharmaceuticals Corporation, NJ, USA

10.1136/thoraxjnl-2014-206260.379

Introduction QMF149 is an investigational inhaled fixed-dose combination of indacaterol acetate and mometasone furoate via the Breezhaler ${ }^{\circledR}$ device for once daily maintenance treatment of asthma and COPD. This double-blind, 12-week study compared

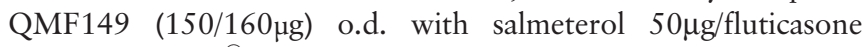
$500 \mu$ g, $\left(\right.$ Seretide $^{\circledR}$; SFC) b.i.d. in patients with moderate to very severe COPD.

Objectives Primary objective of the study was to demonstrate the non-inferiority of QMF149 vs SFC in terms of trough FEV at Week 12. Main secondary objectives were to compare the efficacy of QMF149 vs SFC in terms of dyspnoea via Transition Dyspnoea Index (TDI), health status via St. George Respiratory Questionnaire (SGRQ), rescue medication, exacerbations and safety during the treatment period.

Results 629 patients (mean $\mathrm{FEV}_{1}$ 46.51\% predicted, QMF149 n $=316$; SFC $\mathrm{n}=313$ ) were randomised. The primary objective was met. QMF149 showed significant improvement in trough $\mathrm{FEV}_{1}$ vs SFC (LSM treatment difference [LSMTD] 56mL; p < 0.001). QMF149 improved significantly TDI (LSMTD 0.5; p < $0.026)$ and numerically SGRQ $(-1.66, p=0.093)$ vs SFC. QMF149 significantly prolonged the time to first moderate or severe exacerbation with a $49 \%$ reduction in hazard ratio (hazard ratio [HR] 0.51 ; CI $0.298,0.855 ; \mathrm{p}=0.011$ ) and was associated with $44 \%$ reduction in the number of moderate or severe exacerbations (rate ratio [RR] 0.56; CI 0.331, 0.937; p = 0.028). A significantly greater percentage of days with no rescue medication (LSMTD 6.26\%; $\mathrm{p}=0.007$ ) and significantly fewer rescue medication use was observed with QMF149 (daily number of puffs LSMTD -0.47; p $=0.003$ ). Both treatments were well tolerated with low incidence of AEs.

Conclusion When compared with SFC, QMF149 significantly improves trough $\mathrm{FEV}_{1}$ and dyspnoea, reduces exacerbations and rescue medication use in patients with moderate to very severe COPD.

\section{P252 GOLD CATEGORY AND OPTIMAL MANAGEMENT : A CANADIAN PERSPECTIVE}

K Safka, L Mclvor, A Mclvor. McMaster University, Hamilton, Ontario, Canada

\subsection{6/thoraxjnl-2014-206260.380}

Hypothesis Current Canadian guidelines and GOLD strategy for COPD management provide a treatment algorithm based on current symptoms and exacerbation history. We wished to assess COPD patient current objective, subjective symptoms, quality of life and exacerbation history of a random sample in primary 